\title{
Output Power Smoothing of Grid-Tied PMSG-Based Variable Speed Wind Turbine Using Optimal Controlled SMES
}

\author{
Mohammed H. Qais ${ }^{1}$, Hany M. Hasanien ${ }^{2}$, Saad Alghuwainem ${ }^{1}$ and Mohammed A. Elgendy ${ }^{3}$ \\ ${ }^{1}$ Electrical Department, Faculty of Engineering, King Saud University, Riyadh 11421, Saudi Arabia (e-mail: mqais@ ksu.edu.sa; \\ saadalgh@ksu.edu.sa); ${ }^{2}$ Electrical Power and Machines Department, Faculty of Engineering, Ain Shams University, Cairo 11517, \\ Egypt (e-mail: hanyhasanien@ieee.org); ${ }^{3}$ Electrical Power Research Group, School of Engineering, Newcastle University, Newcastle
}

Upon Tyne, NE1 7RU, UK (e-mail: mohammed.elgendy@ncl.ac.uk)

\begin{abstract}
Due to the stochastic nature of wind speed, energy storage systems are used to reduce the fluctuations of the output power of wind farms. In this paper, the superconducting magnetic energy storage (SMES) is used to smoothen the output power of a permanent magnet synchronous generator (PMSG) driven by a variable speed wind turbine. The PMSG is connected to the grid through a back-to-back converter. The SMES is connected to the DC link of the back-to-back converter through an asymmetrical converter. The Grey Wolf Optimizer (GWO) is used to find the optimal parameters of a proportionalintegral (PI) controller used to regulate the charge and discharge operation of the SMES unit. The grid-tied PMSG wind turbine system is modelled and simulated using PSCAD/EMTDC software. Wind speed data measured at Zaafarana wind farm, Egypt is used in evaluating the system's performance. Simulation results revealed that the optimal controlled SMES has smoothened the output wind power and reduced the total harmonic distortion of it.
\end{abstract}

Index Terms- Energy storage system, PMSG, SMES, Grey wolf optimizer, wind power smoothing.

\section{INTRODUCTION}

Wind power generation is increasing dramatically due to its cost decreasing [1], where $51.3 \mathrm{GW}$ wind power is installed around the world in 2018, with the expectation of similar installations in the coming years [2]. However, the wind energy source is an uncontrolled source by nature, where the wind speed is varying randomly [3]. These speed variations cause undesirable wind power fluctuations [4], which affect the voltage and frequency regulation and increase the total harmonic distortion of the connected grid [5]. Therefore, many techniques are used to smoothen the wind power such as pitch angle control [6], [7], rotor inertia [8]-[10], and flywheel storage [11], [12]. These techniques are based on the mechanical system of the wind turbine, where their response is slow. On the other hand, the energy storage systems (ESSs) are used to improve the performance of wind power plants (WPPs) during wind speed variations [13]. Different types of ESSs have been used to smoothen the output power of WPPs such as battery energy storage system (BESS) [14]-[16], superconducting magnetic energy storage (SMES) [17]-[19], and electric double-layer capacitor [20], [21]. The merits of SMES among other ESSs are: 1) higher storage efficiency; 2) rapid response to charge and discharge; 3) longer lifetime which exceeds 30 years. However, the cost of SMES unit still high due to the high capital cost of superconducting wires, the cost of the cooling system, and the cost of power electronic circuits. On the other hand, the annual operational cost of the SMES is lower than other ESSs [22], [23].

These ESSs require an additional power conversion stage, which means additional cost [24]. Many WPPs configurations have been used depending on the wind speed variations and generator type [25]. Recently, the gearless (directly-coupled) permanent magnet synchronous generator (PMSG) driven by variable speed wind turbine is gaining popularity. The directly-coupled PMSG operates at low rotor speeds due to its high number of rotor poles and it eliminates gearbox losses and excitation losses. PMSG is connected to the grid through a back-to-back converter due to the frequency variations at the generator side [26]. The back-to-back converter includes a machine side converter (MSC) that operates as a rectifier and a grid side inverter (GSI).

Fortunately, the grid-tied PMSG based wind power system has a DC link in the back-to-back converter, to which the ESSs can be connected using a DC/DC converter [14]. The Buck-Boost converter is used with BESS and Supercapacitors [27], whereas the bidirectional DC-DC chopper (asymmetrical converter) is used with SMES systems [28]. In the recent literature survey, many control techniques have been proposed to smoothen the output power using ESSs. Proportionalintegral (PI) controllers [17], fuzzy controllers [6], [29], and artificial neural network (ANN) [4] have been used in the control system of DC/DC converters. Generating an appropriate reference signal is the most important point in the output power smoothing [13]. Many researchers used constant reference signals which may result in total discharge of the stored energy [24]. Furthermore, using optimal controllers 
with appropriate reference signal will decrease the stress on the ESSs and smoothen the output power. While the PI controller is simple and has good performance, its tuning is not an easy task, especially in a complex system like the one considered in this paper. Many algorithms have been used to find the optimal parameters of PI controllers such as particle swarm optimizer (PSO) [19], Tagushi method [30], and affine projection algorithm [31].

In this paper, optimal control is developed to regulate the charging and discharging of an SMES unit in order to smoothen the output power of a direct-coupled PMSG based wind turbine system. Grey wolf optimizer (GWO) is used to find the optimal parameters of PI controllers placed in the control system of the DC/DC converter of the SMES unit. The reference signal for power regulation is generated by feeding the generated wind power to a low-pass filter and using the filter output as the reference signal. The proposed system is modelled and simulated using PSCAD/EMTDC software. Real wind speed data is used to evaluate the performance of the system. Simulation results reveal that the proposed system has smoothened the injected wind power into the grid and reduced the total harmonic distortion (THD) of injected wind power.

\section{POWER SYSTEM MODEL}

The grid-tied PMSG based wind power system considered in this study is shown in Fig. 1. It includes a wind turbine, a PMSG with single-mass shaft model, a back-to-back converter, DC capacitor, braking resistor, SMES unit, a gridside LC filter, a step-up transformer, double paralleled transmission line, and grid model (voltage source controlled).

\section{A. Wind Turbine Model}

The horizontal-axis three-blade wind turbine is used to capture the kinetic energy of wind into mechanical power $\left(P_{m}\right)$, which is expressed as follows [32]

$$
\begin{gathered}
P_{m}=0.5 \rho C_{p}(\lambda, \beta) A v^{3} \\
\mathrm{C}_{\mathrm{p}}(\lambda, \beta)=0.73\left(\frac{151}{\lambda_{i}}-0.58 \beta-0.002 \beta^{2.14}-13.2\right) \mathrm{e}^{-\frac{18.4}{\lambda_{i}}} \\
\frac{1}{\lambda_{i}}=\frac{1}{\lambda+0.02 \beta}-\frac{0.03}{1+\beta^{3}} \\
\lambda=\frac{R \omega_{m}}{v} \\
P_{\max }=\frac{1}{2} \rho A\left(\frac{\omega_{m} R}{\lambda_{\text {opt }}}\right)^{3} C_{\text {Popt }}
\end{gathered}
$$

where $C_{p}, \beta, \lambda, \rho, R, A, v, P_{\text {max }}, \lambda_{\text {opt }}$, and $C_{\text {Popt }}$ are the power coefficient, pitch-angle, tip-speed-ratio (TSR), air density, blades length, swept area, wind speed, maximum power, optimum TSR, and optimum power coefficient, respectively.

\section{B. PMSG Model}

The terminal voltages of PMSG are written in the d-q axis as follows [33]-[35]

$$
\left(\begin{array}{l}
v_{s d} \\
v_{s q}
\end{array}\right)=-R_{s}\left(\begin{array}{l}
i_{s d} \\
i_{s q}
\end{array}\right)-\frac{d}{d t}\left(\begin{array}{l}
L_{d} i_{s d} \\
L_{q} i_{s q}
\end{array}\right)+\omega_{e}\left(\begin{array}{l}
-L_{q} i_{s q} \\
L_{d} i_{s d}+\psi_{f}
\end{array}\right)
$$

where $v_{s d}, v_{s q}, i_{s d}, i_{s q}, L_{d}, L_{q}, R_{s}, \omega_{e}$, and $\psi_{f}$ are the stator voltages and currents in $\mathrm{d}-\mathrm{q}$ frame, the $\mathrm{d}$-q frame inductance, stator resistance, electrical rotational speed, and the linkage flux, respectively. The drive-train is modelled as a singleshaft model as follows:

$$
\begin{gathered}
j \frac{d \omega_{m}}{d t}+D_{c} \omega_{m}=T_{m}-T_{e} \\
\omega_{e}=\frac{p}{2} \omega_{m}
\end{gathered}
$$

where $T_{m}, T_{e}, \omega_{m}, D_{c}, j$, and $P$ are the mechanical torque, electrical torque mechanical rotor speed, damping coefficient, rotor inertia, and the number of poles, respectively.

\section{MSC Model and Control}

The MSC is a two-level voltage source converter (VSC) constructed from six insulated gate bipolar transistors (IGBTs) in three leg bridge. The cascaded control is used to generate pulse width modulation (PWM) to trigger the IGBTs as depicted in Fig. 2. The MSC operates as a rectifier, which converts the AC power to DC power.

\section{GSI Model and Control}

The GSI has the same construction as the MSC but operates as an inverter, converting the DC power to $\mathrm{AC}$ power. The cascaded control shown in Fig. 3 is used to generate the PWM to trigger the IGBTs. The phase locked loop is used to synchronize the inverter voltage with the grid voltage.

\section{SMES UNIT}

\section{A. SMES unit construction}

The superconducting magnetic energy storage includes a superconducting coil wound around a superconducting magnet and a DC/DC chopper for charging and discharging the coil. The electrical energy is stored in the magnetic field produced by the DC current flowing in the superconducting coil. The coil is immersed in a helium vessel to keep the coil cold and at the superconductivity state. The value of SMES coil inductance is $21.1 \mathrm{H}$ for real practical $10 \mathrm{MVA} / 20 \mathrm{MJ}$ SMES unit that is installed in Kameyama, Japan. The DC/DC chopper includes two IGBTs and two diodes as depicted in Fig. 4. For charging state, the IGBTs s1 and s2 are switched on by a controller. For discharging state, the s1 and s2 are switched off and the SMES will discharge through the diodes. For no charging and discharging state, the dc current will circulate between the coil, s2, and the diode D2, as depicted in Fig. 4.

\section{B. SMES unit control}

The control system manages the charging and discharging of the SMES unit according to the generated reference signal. The reference signal is generated by entering the wind power into the low-pass filter with unity gain and time constant 100 sec. Therefore, the output power of GSI to the grid $\left(P_{\text {grid }}\right)$ is regulated with the generated reference power $\left(P_{\text {ref }}\right)$ as depicted in Fig. 5. The PI controller is used to regulate the error signal 
to produce the duty cycle $D$, which is compared with a triangular signal with frequency $1000 \mathrm{~Hz}$. The charging and discharging state happened if $D$ is more or less than 0.5 . If the $D$ is 0.5 then no charging or discharging process (Idle).

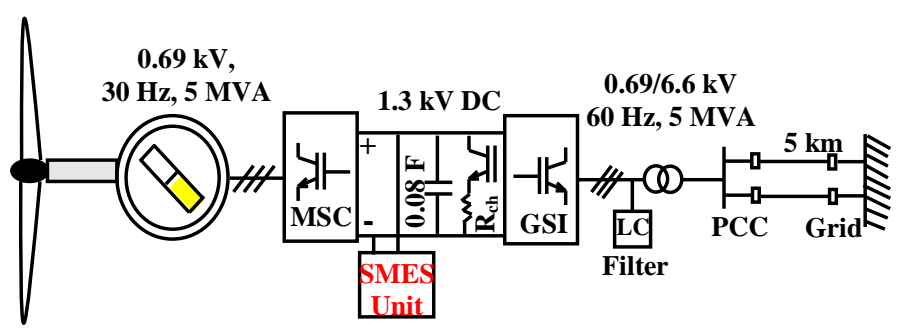

Fig. 1. Power system model

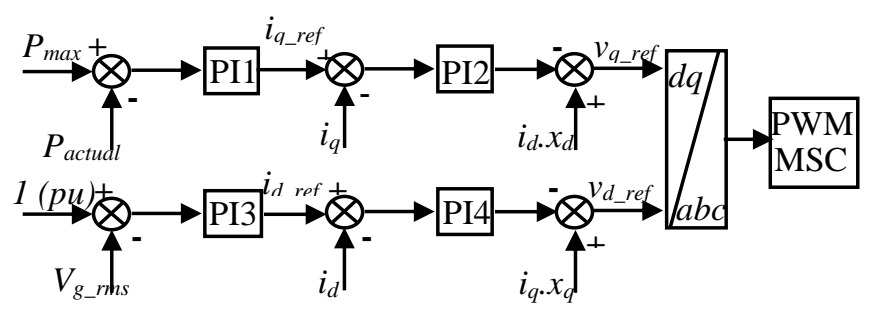

Fig. 2 MSC control

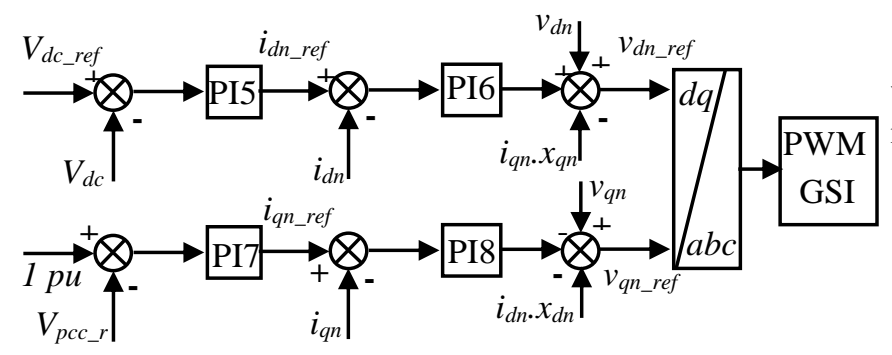

Fig. 3 GSI control

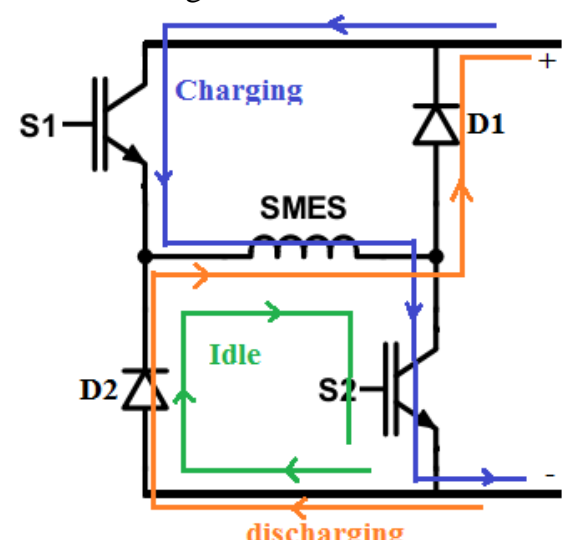

Fig. 4 SMES Unit

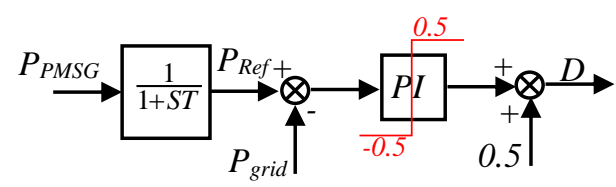

Fig. 5 Control of SMES unit

\section{OPTIMIZATION PROCEDURE}

In this section, the grey wolf optimizer (GWO) is used to find the optimal parameters of the PI controller of the control system of SMES unit by minimizing the objective function in (9). In previous work, the GWO is used to find the optimal parameters of the PI controllers of MSC and GSI control systems [36].

$$
f_{o b j}=\int\left(P_{r e f}-P_{g r i d}\right)^{2} d t
$$

\section{A. GWO algorithm}

The GWO is an efficient and fast algorithm with a few control parameters, which can be modelled easily in PSCAD. The GWO is found by Mirjalili et al., in 2014 [37], [38]. This algorithm stimulates the hunting behaviour of grey wolves' society. In this society, there is a leader $(\alpha)$, followed by $(\beta)$ that can contribute to the decision with $\alpha$. The remaining followers are $\delta$ and $\omega$ as depicted in Fig. 6.

The grey wolves start seeking for the prey, then encircling it, and finally hunting it. The mathematical model of encircling the prey is written as follows:

$$
\begin{aligned}
& \vec{D}=\left|\vec{C} \cdot \vec{X}_{p i}-\vec{X}_{i}\right| \\
& \vec{X}_{i+1}=\vec{X}_{p i}-\vec{A} \cdot \vec{D}
\end{aligned}
$$

where $X_{i}$ is the grey wolf position, $X_{p i}$ is the prey position, $D$ is the distance, $A$ and $C$ are vectors calculated as follows:

$$
\begin{gathered}
\vec{a}=2-2 \times t / \text { Max_iter } \\
\vec{A}=2 \vec{a} \cdot \vec{r}_{1}-\vec{a} \\
\vec{C}=2 \cdot \vec{r}_{2}
\end{gathered}
$$

where $r_{1}$ and $r_{2}$ are random numbers between $[0,1]$. The parameter $a$ is decreasing linearly from 2 to 0 with iterations increasing. The exploration or searching stage of the GWO can be achieved when $|A|>1$. The exploitation or hunting stage can be achieved when $|A|<1$. The hunting is led by $\alpha$ entity with support of $\beta$ and $\delta$ entities as in (15)-(17). Fig.7 shows the pseudo code of the GWO.

$$
\begin{gathered}
\vec{D}_{\alpha}=\left|\vec{C}_{1} \cdot \vec{X}_{\alpha i}-\vec{X}_{i}\right|, \quad \vec{D}_{\beta}=\left|\vec{C}_{2} \cdot \vec{X}_{\beta i}-\vec{X}_{i}\right|, \\
\vec{D}_{\delta}=\left|\vec{C}_{3} \cdot \vec{X}_{\delta i}-\vec{X}_{i}\right| \\
\vec{X}_{1}=\vec{X}_{\alpha i}-\vec{A}_{1} \cdot \vec{D}_{\alpha}, \vec{X}_{2}=\vec{X}_{\beta i}-\vec{A}_{2} \cdot \vec{D}_{\beta}, \\
\vec{X}_{3}=\vec{X}_{\delta i}-\vec{A}_{3} \cdot \vec{D}_{\delta} \\
\vec{X}_{i+1}=\frac{\vec{X}_{1}+\vec{X}_{2}+\vec{X}_{3}}{3}
\end{gathered}
$$




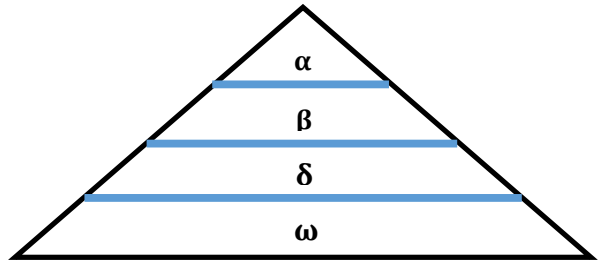

Fig. 6 Grey wolf society

Initialize the searchagents positions $X_{i}, X_{\alpha}, X_{\beta}$, and $X_{\delta}$

Compute the fitness of each searchagents

Initialize a, A, and C by Eq. (12), (13), and (14)

while $t<$ Max_iter

for each search agent

Update the position of current searchagent using

Eq. (17)

end for

Compute the fitness of all search agents

Update $a$, $A$, and $C$

Update $X_{\alpha}, X_{\beta}$, and $X_{\delta}$

$t=t+1$

end while

return the best position $X_{\alpha}$

Fig. 7 Pseudo code of GWO algorithm

\section{B. Optimization results}

The GWO is applied to minimize the objective function in (9), which is the integral-square of error input of the PI controller in SMES control system. The convergence curve of the objective function value during 800 iterations is depicted in Fig. 8. In addition, the optimal gain and time constant of PI controllers that are attained by the GWO are 2.979 and 0.005 , respectively.

\section{Simulation Results}

In this section, the optimally controlled SMES unit is used to smoothen the output power of PMSG driven by a variable speed wind turbine. The power system model, shown in Fig. 1 , is simulated in PSCAD/EMTDC. In this study, real wind speed data, measured at Zaafarana wind farm in Egypt on December 1, 2014, are used. As shown in Fig. 9-(a), within $400 \mathrm{sec}$ the wind speed varies between 8.5 and $14 \mathrm{~m} / \mathrm{s}$, where the base wind speed of the wind turbine is $12 \mathrm{~m} / \mathrm{s}$. The rotor speed response is depicted in Fig. 9-(b), which varies between $1 \mathrm{pu}$ and $0.76 \mathrm{pu}$, where the pitch angle controller is activated when the wind speed exceeds the base wind speed and keeps the rotor speed at $1 \mathrm{pu}$. The grid voltage at the point of common coupling (PCC) is kept at 1 pu without fluctuations (smooth) when using SMES and with noticeable fluctuations without SMES, as shown in Fig. 9-(c). The reactive power response is kept at 0 level for unity power factor as shown in Fig. 9-(d). The active power that is generated by wind turbine and the reference power that is generated for power smoothing are depicted in Fig. 9-(e). The reference power is produced by filtering the active power of wind generator using low-pass filter with first order transfer function. The transmitted active power to the grid at the PCC and the reference power are depicted in Fig. 9-(f), where the delivered active power to the grid is smoothed and identical with the reference power. The variation of SMES power during discharge and charge is shown in Fig. 9-(g), where it discharges power if the wind power is less than reference power and it is charged if the wind power is more than the reference power. The total harmonic distortion (THD) of wind power at PCC is analyzed with and without SMES. It is obvious in Fig. 9-(h) that the THD is very small with the use of SMES and could be significantly larger without using SMES.

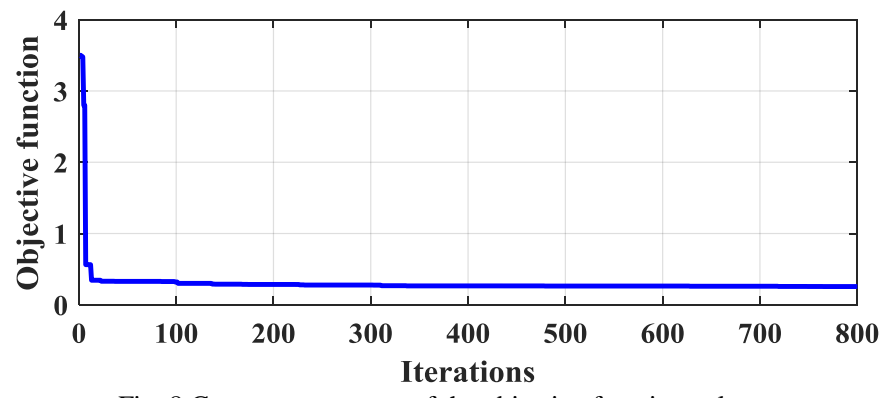

Fig. 8 Convergence curve of the objective function value

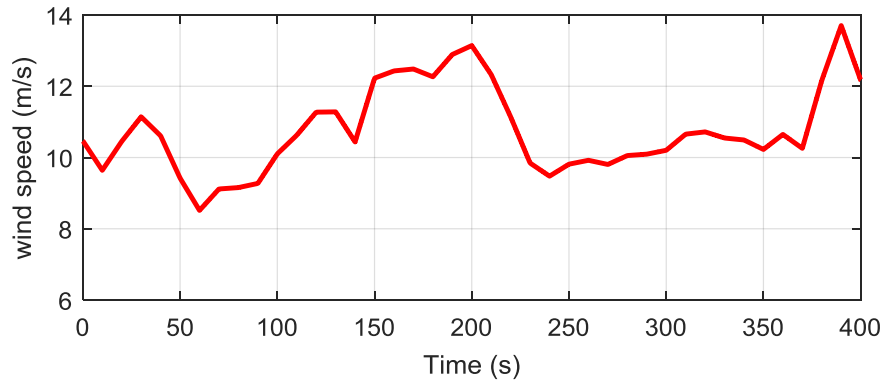

(a)

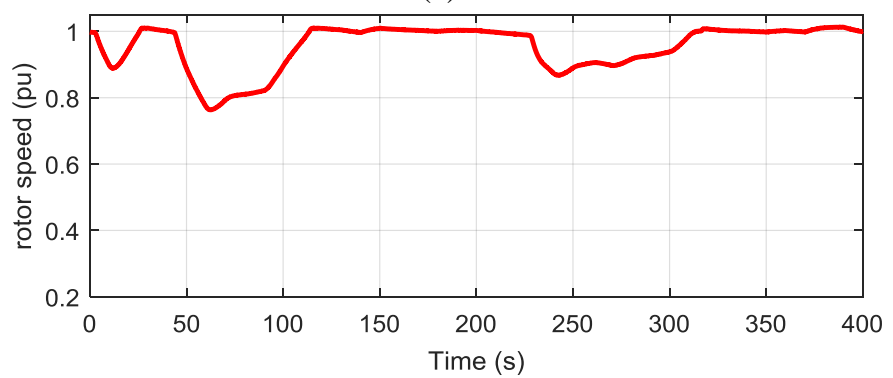

(b)

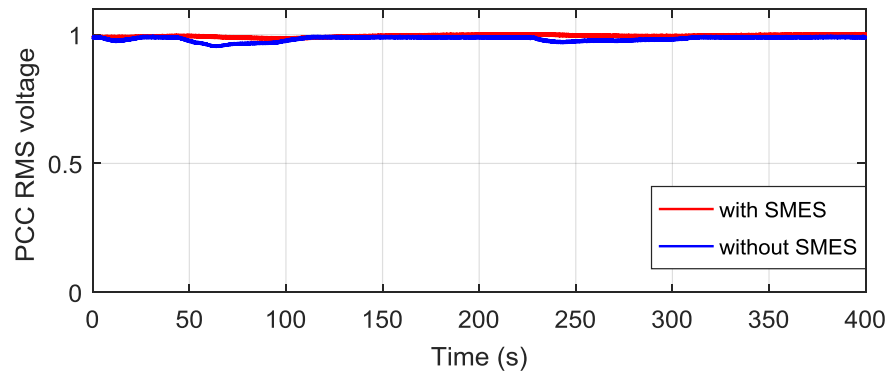

(c) 


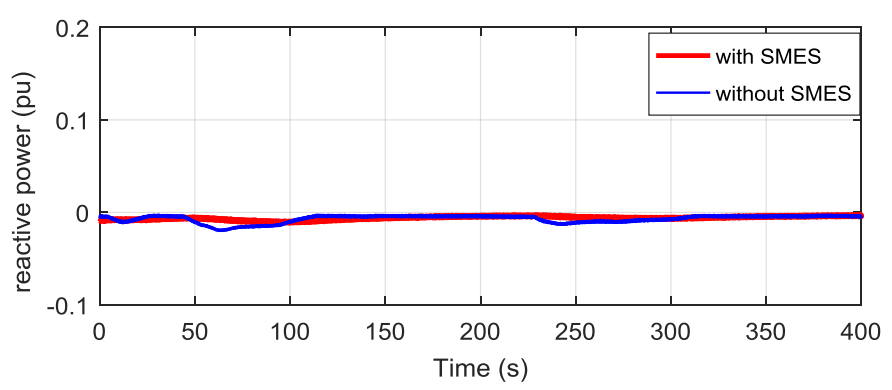

(d)

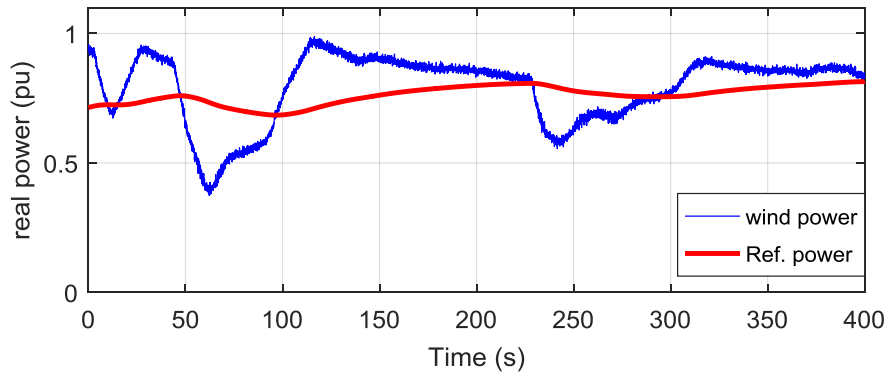

(e)

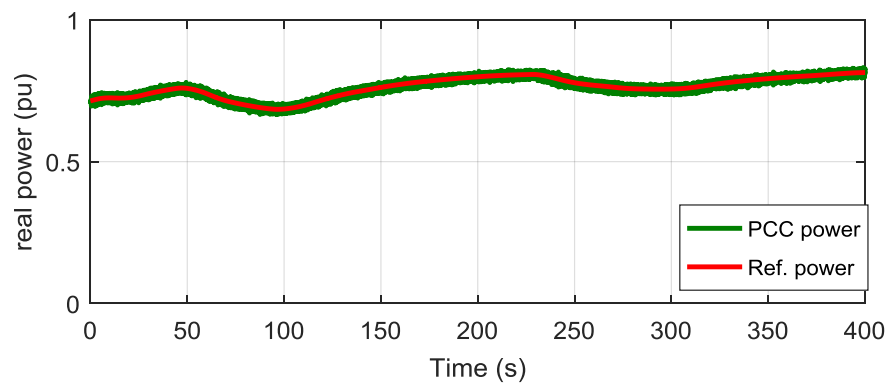

(f)

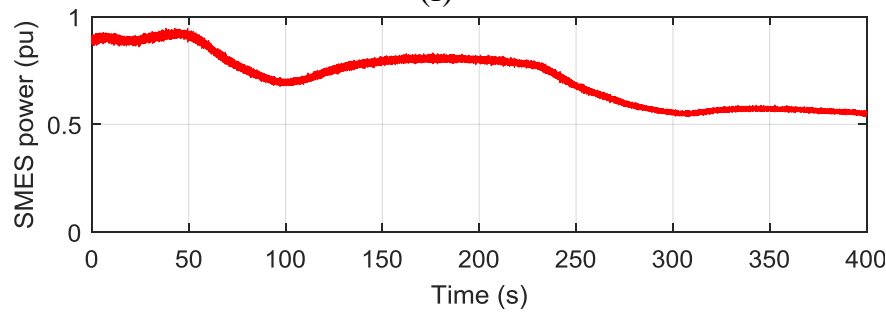

(g)

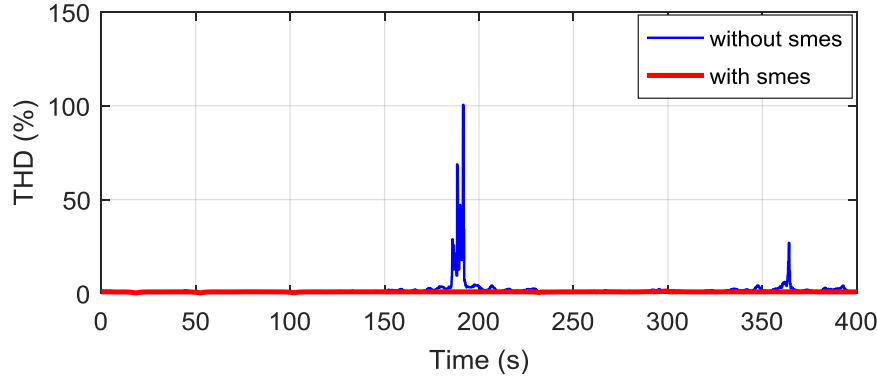

(h)

Fig. 9 Time response of a) wind speed; b) rotor speed; c) PCC voltage; d) reactive power; e) output power at PMSG; f) output smoothed power at PCC; g) SMES power; h) THD

\section{CONCLUSION}

This paper proposed an optimal controlled SMES system to smoothen the output wind power. The grey wolf optimizer (GWO) is used to find the optimal parameters (gain and time constant) of the PI controller by minimizing the proposed objective function. The proposed SMES unit is applied to smoothen the output power of PMSG driven by a variable speed wind turbine. A real wind speed data with wide range variation between 8.5 and $14 \mathrm{~m} / \mathrm{s}$ are used to verify the effectiveness of the proposed SMES system. The simulation results revealed that the fluctuations of measured voltage and power at the point of common coupling are smoothed with using SMES unit. In addition, the total harmonic distortion (THD) is very small with the use of SMES.

\section{REFERENCES}

[1] "Renewables 2018 Global status report," 2018. [Online]. Available: http://www.ren21.net/status-of-renewables/globalstatus-report/. [Accessed: 05-Jan-2019].

[2] "Global Wind Report 2018," GWEC, 2019. [Online]. Available: http://gwec.net/. [Accessed: 01-May-2019].

[3] M. H. Qais, H. M. Hasanien, and S. Alghuwainem, "Output power smoothing of grid-connected permanent-magnet synchronous generator driven directly by variable speed wind turbine: a review," J. Eng., vol. 2017, no. 13, pp. 1755-1759, 2017.

[4] S. M. Muyeen, H. M. Hasanien, and J. Tamura, "Reduction of frequency fluctuation for wind farm connected power systems by an adaptive artificial neural network controlled energy capacitor system," IET Renewable Power Generation, vol. 6, no. 4. pp. 226-235, 2012.

[5] T. Ikegami, C. T. Urabe, T. Saitou, and K. Ogimoto, "Numerical definitions of wind power output fluctuations for power system operations," Renew. Energy, vol. 115, pp. 6-15, 2018.

[6] M. A. Chowdhury, N. Hosseinzadeh, and W. X. Shen, "Smoothing wind power fluctuations by fuzzy logic pitch angle controller," Renew. Energy, vol. 38, no. 1, pp. 224-233, Feb. 2012.

[7] A. M. Howlader, T. Senjyu, and A. Y. Saber, "An Integrated Power Smoothing Control for a Grid-Interactive Wind Farm Considering Wake Effects," IEEE Systems Journal, vol. 9, no. 3. pp. 954-965, 2015.

[8] A. Uehara, T. Senjyu, A. Yona, T. Funabashi, and C.-H. Kim, "A fuzzy-logic based output power smoothing method of WECS with permanent magnet synchronous generator using inertia of wind turbine," J. Int. Counc. Electr. Eng., vol. 1, no. 3, pp. 309-316, Jul. 2011.

[9] A. Abedini and A. Nasiri, "Output Power Smoothing for Wind Turbine Permanent Magnet Synchronous Generators Using Rotor Inertia," Electr. Power Components Syst., vol. 37, no. 1, pp. 1-19, Dec. 2008.

[10] S. G. Varzaneh, G. B. Gharehpetian, and M. Abedi, "Output power smoothing of variable speed wind farms using rotorinertia," Electr. Power Syst. Res., vol. 116, pp. 208-217, Nov. 2014.

[11] F. Islam, H. Hasanien, A. Al-Durra, and S. M. Muyeen, "A new control strategy for smoothing of wind farm output using short-term ahead wind speed prediction and Flywheel energy storage system," in 2012 American Control Conference (ACC), 2012, pp. 3026-3031. 
[12] T. A. Taj, H. M. Hasanien, A. I. Alolah, and S. M. Muyeen, "Transient stability enhancement of a grid-connected wind farm using an adaptive neuro-fuzzy controlled-flywheel energy storage system," IET Renew. Power Gener., vol. 9, no. 7, pp. 864-864(0), Sep. 2015.

[13] A. M. Howlader, N. Urasaki, A. Yona, T. Senjyu, and A. Y. Saber, "A review of output power smoothing methods for wind energy conversion systems," Renew. Sustain. Energy Rev., vol. 26, pp. 135-146, Oct. 2013.

[14] B. Meghni, D. Dib, and A. T. Azar, "A second-order sliding mode and fuzzy logic control to optimal energy management in wind turbine with battery storage," Neural Comput. Appl., pp. 1-18, 2016.

[15] G. Xu, L. Xu, and L. Yao, "Wind turbines output power smoothing using embedded energy storage systems," J. Mod. Power Syst. Clean Energy, vol. 1, no. 1, pp. 49-57, 2013.

[16] Y. Zhu, H. Zang, L. Cheng, and S. Gao, "Output Power Smoothing Control for a Wind Farm Based on the Allocation of Wind Turbines," Applied Sciences , vol. 8, no. 6. 2018.

[17] H. M. Hasanien, "A Set-Membership Affine Projection Algorithm-Based Adaptive-Controlled SMES Units for Wind Farms Output Power Smoothing," IEEE Transactions on Sustainable Energy, vol. 5, no. 4. pp. 1226-1233, 2014.

[18] H. M. Hasanien and A. Y. Abdelaziz, "An Adaptivecontrolled Superconducting Magnetic Energy Storage Unit for Stabilizing a Grid-connected Wind Generator," Electr. Power Components Syst., vol. 43, no. 8-10, pp. 1072-1079, Jun. 2015.

[19] H. M. Hasanien and S. M. Muyeen, "Particle swarm optimization-based superconducting magnetic energy storage for low-voltage ride-through capability enhancement in wind energy conversion system," Electr. Power Components Syst., vol. 43, no. 11, pp. 1278-1288, Jul. 2015.

[20] S. I. Gkavanoudis and C. S. Demoulias, "A combined fault ride-through and power smoothing control method for fullconverter wind turbines employing Supercapacitor Energy Storage System," Electr. Power Syst. Res., vol. 106, pp. 6272, Jan. 2014.

[21] A. Abedini and A. Nasiri, "Applications of super capacitors for PMSG wind turbine power smoothing," 2008 34th Annual Conference of IEEE Industrial Electronics. pp. 3347-3351, 2008.

[22] X. Zhou et al., "Cost Estimation Models of MJ Class HTS Superconducting Magnetic Energy Storage Magnets," IEEE Trans. Appl. Supercond., vol. 28, no. 4, pp. 1-5, 2018.

[23] S. Nomura, T. Shintomi, S. Akita, T. Nitta, R. Shimada, and S. Meguro, "Technical and Cost Evaluation on SMES for Electric Power Compensation," IEEE Trans. Appl. Supercond., vol. 20, no. 3, pp. 1373-1378, 2010.

[24] M. Jannati, S. H. Hosseinian, B. Vahidi, and G. Li, "A significant reduction in the costs of battery energy storage systems by use of smart parking lots in the power fluctuation smoothing process of the wind farms," Renew. Energy, vol. 87, Part 1, pp. 1-14, Mar. 2016.

[25] M. H. Qais, H. M. Hasanien, and S. Alghuwainem, "Low voltage ride-through capability enhancement of gridconnected permanent magnet synchronous generator driven directly by variable speed wind turbine: a review," J. Eng., vol. 2017, no. 13, pp. 1750-1754, 2017.

[26] M. A. Soliman, H. Hasanien, H. Z. Azazi, E. E. El-kholy, and S. A. Mahmoud, “An Adaptive Fuzzy Logic Control Strategy for Performance Enhancement of a Grid-Connected PMSGBased Wind Turbine," IEEE Trans. Ind. Informatics, vol. 15, no. 6, pp. 3163-3173, June 2019.
[27] K. Zhang, C. Mao, J. Lu, D. Wang, J. Zhang, and X. Chen, "Power control of directly driven wind generation system based on superconducting magnetic energy storage," Electr. Power Components Syst., vol. 43, no. 7, pp. 747-758, Apr. 2015.

[28] C. Huang, X. Y. Xiao, Z. Zheng, and Y. Wang, "Cooperative Control of SFCL and SMES for Protecting PMSG-Based WTGs Under Grid Faults," IEEE Trans. Appl. Supercond., vol. 29, no. 2, pp. 1-6, 2019.

[29] A. M. Howlader, N. Urasaki, A. Pratap, T. Senjyu, and A. Y. Saber, "A fuzzy control strategy for power smoothing and grid dynamic response enrichment of a grid-connected wind energy conversion system," Wind Energy, vol. 17, no. 9, pp. 1347-1363, 2014.

[30] H. M. Hasanien and S. M. Muyeen, "A Taguchi approach for optimum design of proportional-integral controllers in cascaded control scheme," IEEE Trans. Power Syst., vol. 28, no. 2, pp. 1636-1644, 2013.

[31] H. M. Hasanien and S. M. Muyeen, "Affine projection algorithm based adaptive control scheme for operation of variable-speed wind generator," IET Generation, Transmission \& Distribution, vol. 9, no. 16. pp. 2611-2616, 2015.

[32] M. H. Qais, H. M. Hasanien, and S. Alghuwainem, "Enhanced salp swarm algorithm: Application to variable speed wind generators," Eng. Appl. Artif. Intell., vol. 80, pp. 82-96, 2019.

[33] O. P. Mahela and A. G. Shaik, "Comprehensive overview of grid interfaced wind energy generation systems," Renew. Sustain. Energy Rev., vol. 57, pp. 260-281, May 2016.

[34] B. Zaker, G. B. Gharehpetian, and M. Karrari, "Improving Synchronous Generator Parameters Estimation Using d-q Axes Tests and Considering Saturation Effect," IEEE Trans. Ind. Informatics, vol. PP, no. 99, p. 1, 2017.

[35] D. Reddy and S. Ramasamy, "Design of RBFN Controller Based Boost Type Vienna Rectifier for Grid-Tied Wind Energy Conversion System," IEEE Access, vol. 6, pp. 31673175, 2018.

[36] M. H. Qais, H. M. Hasanien, and S. Alghuwainem, “A Grey Wolf Optimizer for Optimum Parameters of Multiple PI Controllers of a Grid-Connected PMSG Driven by Variable Speed Wind Turbine," IEEE Access, vol. 6, no. 1, pp. 4412044128, 2018.

[37] S. Mirjalili, S. M. Mirjalili, and A. Lewis, "Grey Wolf Optimizer," Adv. Eng. Softw., vol. 69, no. Supplement C, pp. 46-61, 2014.

[38] M. H. Qais, H. M. Hasanien, and S. Alghuwainem, "Augmented grey wolf optimizer for grid-connected PMSGbased wind energy conversion systems," Appl. Soft Comput. J., vol. 69, 2018. 